\title{
BMJ Open Global cardiovascular risk assessment in the primary prevention of cardiovascular disease in adults: systematic review of systematic reviews
}

\author{
Dylan R J Collins, ${ }^{1}$ Alice C Tompson, ${ }^{1}$ Igho J Onakpoya, ${ }^{1}$ Nia Roberts, ${ }^{2}$ \\ Alison M Ward, ${ }^{1}$ Carl J Heneghan ${ }^{1}$
}

To cite: Collins DRJ, Tompson AC, Onakpoya IJ, et al. Global cardiovascular risk assessment in the primary prevention of cardiovascular disease in adults: systematic review of systematic reviews. BMJ Open 2017;7:e013650. doi:10.1136/bmjopen-2016013650

- Prepublication history and additional material is available. To view please visit the journal (http://dx.doi.org/ 10.1136/bmjopen-2016013650).

Received 27 July 2016 Revised 8 November 2016 Accepted 15 December 2016

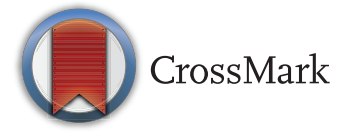

${ }^{1}$ Nuffield Department of Primary Care Health Sciences, Centre for Evidence-Based Medicine, University of Oxford, Oxford, UK

${ }^{2}$ Bodleian Health Care Libraries, University of Oxford, Oxford, UK

Correspondence to Dylan R J Collins; dylan.collins@phc.ox.ac.uk

\section{ABSTRACT}

Objective: To identify, critically appraise and summarise existing systematic reviews on the impact of global cardiovascular risk assessment in the primary prevention of cardiovascular disease (CVD) in adults.

Design: Systematic review of systematic reviews published between January 2005 and October 2016 in The Cochrane Library, EMBASE, MEDLINE or CINAHL databases, and post hoc analysis of primary trials.

Participants, interventions, outcomes: Systematic reviews of interventions involving global cardiovascular risk assessment relative to no formal risk assessment in adults with no history of CVD. The primary outcomes of interest were CVD-related morbidity and mortality and all-cause mortality; secondary outcomes were systolic blood pressure (SBP), cholesterol and smoking.

Results: We identified six systematic reviews of variable but generally of low quality (mean Assessing the Methodological Quality of Systematic Reviews 4.2/ 11 , range $0 / 11$ to $7 / 11$ ). No studies identified by the systematic reviews reported CVD-related morbidity or mortality or all-cause mortality. Meta-analysis of reported randomised controlled trials (RCTs) showed small reductions in SBP (mean difference (MD) $-2.22 \mathrm{~mm} \mathrm{Hg}(95 \% \mathrm{Cl}-3.49$ to -0.95$) ;\left.\right|^{2}=66 \% ; n=9$; GRADE: very low), total cholesterol (MD $-0.11 \mathrm{mmol} / \mathrm{L}$ $(95 \% \mathrm{Cl}-0.20$ to -0.02$) ; I^{2}=72 \%$; $n=5$; GRADE: very low), low-density lipoprotein cholesterol (MD $-0.15 \mathrm{mmol} / \mathrm{L}(95 \% \mathrm{Cl}-0.26$ to -0.05$), \mathrm{I}^{2}=47 \%$; $\mathrm{n}=4$; GRADE: very low) and smoking cessation (RR $1.62(95 \%$ Cl 1.08 to 2.43$) ; I^{2}=17 \% ; n=7$; GRADE: low). The median follow-up time of reported RCTs was 12 months (range 2-36 months).

Conclusions: The quality of existing systematic reviews was generally poor and there is currently no evidence reported in these reviews that the prospective use of global cardiovascular risk assessment translates to reductions in CVD morbidity or mortality. There are reductions in SBP, cholesterol and smoking but they may not be clinically significant given their small effect size and short duration. Resources need to be directed to conduct high-quality systematic reviews focusing on hard patient outcomes, and likely further primary RCTs.

Trial registration number: CRD42015019821.
Strengths and limitations of this study

- This systematic review summarises evidence from six systematic reviews on the use of global cardiovascular disease (CVD) risk assessment for the primary prevention of CVD in adults and reports important patient outcomes.

- The quality of the systematic reviews was assessed using Assessing the Methodological Quality of Systematic Reviews and was generally poor, with inconsistencies in methods, outcomes, quality appraisal and reporting.

- Owing to the deficiencies in the reviews, we undertook post meta-analyses, which included further analysis of the identified primary studies within the reviews and quality appraisal using GRADE.

- Our systematic review was strengthened by its broad inclusion criteria, which reduced the chance we missed relevant systematic reviews.

- The findings of our post hoc meta-analyses should be interpreted with caution given the paucity of evidence and low to very low GRADE scores.

\section{INTRODUCTION}

Cardiovascular disease (CVD) is the leading cause of death worldwide. ${ }^{1}$ Contrary to popular belief, death and disability from CVD is also a major burden in low-resource settings $^{2}{ }^{3}$ and despite impressive global reductions in mortality over the last two decades, years-of-life-lost due to CVD is rising in low-income and middle-income countries. ${ }^{4}$ Prevention is therefore a worldwide priority.

Global CVD risk assessment (also referred to as absolute risk assessment, total risk assessment or risk scoring) is an integrated approach to prevention that recognises the hazards of multiple risk factors to determine the absolute risk of experiencing a CVD event in a given time period. Almost all CVD guidelines recommend some form of risk scoring as a 
way to prioritise and plan primary prevention interventions. ${ }^{5-7}$ This practice is entrenched in most highincome countries, ${ }^{5} 68$ and endorsed by the WHO for low-income and middle-income countries. ${ }^{7}$

Even with an abundance of clinical guidance and effective interventions targeting modifiable risk factors, the majority of patients at risk do not achieve sufficient risk factor control. ${ }^{9-14}$ In jurisdictions where risk scoring is part of routine clinical practice, this may be due to implementation challenges, such as physician attitudes to and understanding of CVD risk assessment, ${ }^{14-16}$ challenges communicating risk to patients and patients' understanding of risk ${ }^{17}$ or lack of a true effect. Although calibration and discrimination studies of prognostic risk score models are important, trials on the prospective use of risk scores in practice are required to determine their impact on patient outcomes.

While the development of global cardiovascular risk assessment has been the focus of much research, ${ }^{19-22}$ there is little certainty about its effectiveness in the prevention of CVD. We conducted a systematic review of systematic reviews to identify, critically appraise and summarise evidence on the impact of global cardiovascular risk assessment in the primary prevention of CVD. We chose to conduct a systematic review of systematic reviews because they can be used to synthesise evidence for a given intervention on a diversity of outcomes, in addition to identifying limitations in the methodology and quality of existing systematic reviews. ${ }^{23}$

\section{METHODS}

We prospectively registered our protocol on PROSPERO (registration CRD42015019821), ${ }^{24}$ and deviations from this plan, which were minor, are described in online supplementary S1 appendix 1.

\section{Search strategy}

We searched the Cochrane Library, EMBASE, MEDLINE and CINAHL databases from January 2005 to October 2016 (see online supplementary S2 appendix 2 for detailed search strategies). We searched from 2005 because we felt that more recent systematic reviews were likely to capture the same primary studies as older systematic reviews. No language restrictions were applied. Search strategies used a mix of Medical Subject Heading $(\mathrm{MeSH})$ terms and keywords and were developed with an information specialist. We supplemented this strategy by handsearching the bibliographies of included reviews, forward citation searching on Google Scholar and Web of Science and by contacting experts.

\section{Inclusion criteria}

We included systematic reviews of studies of any design that included adults ( 18 years of age or older) with no history of CVD (including atrial fibrillation). Reviews were eligible for inclusion if they considered interventions involving global CVD risk assessment relative to no risk assessment, irrespective of who performed the risk assessment, how it was performed and to whom the information was directed. We excluded studies of perioperative CVD risk scores, analogue patients, patients with existing CVD, validation studies and accuracy studies of CVD risk scores.

The primary outcomes of interest were CVD-related morbidity or mortality and all-cause mortality. We secondarily considered systolic blood pressure (SBP), cholesterol and smoking, because together these cause the majority of premature CVD and have effective interventions to treat them. ${ }^{25} 26$

\section{Study selection, data extraction and quality assessment}

Study selection, data extraction and quality assessment was done in two phases. We first screened systematic reviews for inclusion, and then screened primary studies reported in the systematic reviews as required.

Two reviewers screened titles and abstracts for full text review and disagreement was resolved by consensus. We screened full text articles for inclusion using the same method. Two reviewers independently extracted salient characteristics about the included reviews and their description of included studies, including the classification of interventions as either directed toward the patient, provider or the patient and provider. The same reviewers independently assessed methodological quality using the Assessing the Methodological Quality of Systematic Reviews (AMSTAR) checklist. ${ }^{27}$ We documented the method of quality assessment and extracted the quality of primary studies as reported by the review authors. If a primary study was reported by more than one review, we extracted the quality score from the review with the highest AMSTAR rating.

We did not initially plan to extract data from primary studies; however, to address poor or insufficient reporting, or to verify intervention classifications, the second phase involved the same two reviewers extracting additional data from the primary studies as needed. We extracted data from primary studies as reported in systematic reviews and tabulated all results by outcome using Microsoft Excel 2010 and Microsoft Word 2010. In the event of a discrepancy, we used the data reported in the primary study rather than the systematic review. When outcomes were reported at multiple time points in a single study, we selected the longest follow-up time with complete data.

\section{Data synthesis}

We narratively reported systematic reviews and tabulated their salient characteristics, including review, author conclusions and AMSTAR ratings. For our post hoc analysis of primary studies reported by systematic reviews, we used RevMan V.5.3 to construct forest plots and inverse variance-weighted random effects meta-analyses. ${ }^{28}$ One author entered data into RevMan and these were independently verified by a second author. We only included randomised studies in meta-analyses; other study designs or randomised studies with insufficient data to 
meta-analyse were reported narratively. For continuous outcomes, we calculated mean differences and for dichotomous outcomes, risk ratios. We performed subgroup analyses by the intended target of the intervention (patient, provider or both). We imputed standard error (SE) when reasonable, using the average SE of studies reporting the same outcome and in the same subgroup, and in such cases a sensitivity analysis was performed. For each outcome meta-analysed, we used the GRADE methodology to rate the quality of evidence using GRADEpro GDT software. $^{29}{ }^{30}$ This was done by one author and checked by a second; disagreements were resolved by consensus. We used $\mathrm{I}^{2}$ values to estimate statistical heterogeneity.

\section{RESULTS}

We screened 6877 studies for inclusion, 6727 of which were excluded as irrelevant based on title and abstract (figure 1). Following full-text review of 150 studies, six systematic reviews met the inclusion criteria. We excluded 144 articles, the majority $(n=110)$ due to the study design. The six included systematic reviews together reported 122 unique primary studies, 16 of which were relevant based on our inclusion criteria, including adults with no history of CVD and global CVD risk assessment as an intervention relative to no risk assessment. Of these, none reported CVD-related morbidity or mortality or all-cause mortality, 12 reported
Figure 1 Flow diagram of included systematic reviews, primary studies and the outcomes reported.

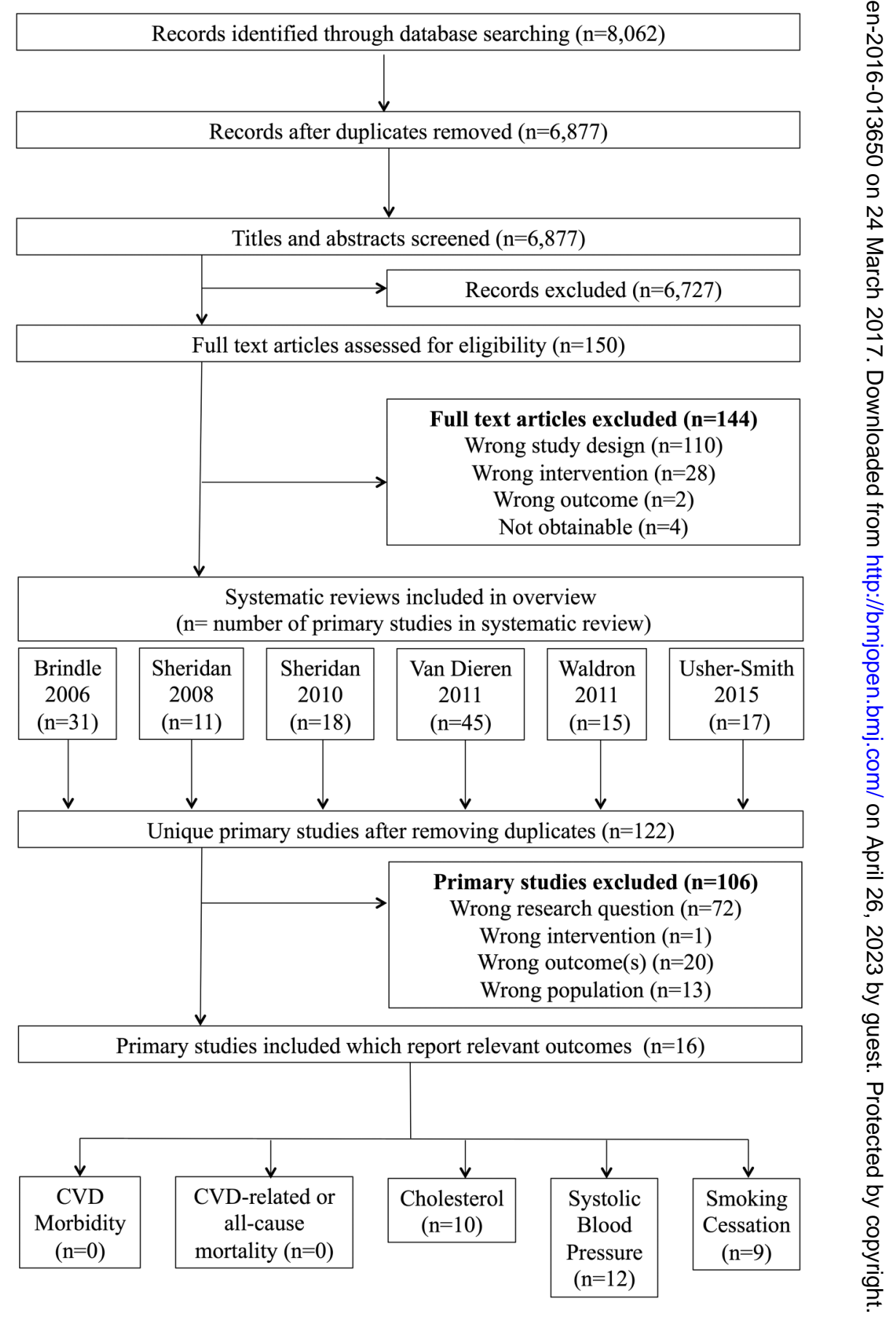


SBP, 10 reported cholesterol and 9 reported smoking cessation (figure 1).

\section{Summary of included systematic reviews}

Characteristics of included systematic reviews are summarised in table 1 . Reviews were generally broad in scope, published from 2006 to 2015, considered all study designs and collectively searched 11 databases. AMSTAR ratings ranged from $0 / 11$ to $7 / 11$ (mean 4.2/11); we did not exclude any reviews based on quality (see online supplementary S3 appendix 3). The conclusions of reviews were consistently of general uncertainty about the impact of cardiovascular risk assessment on hard patient outcomes.

Brindle et $a l^{31}$ (AMSTAR 4/11) sought to determine the accuracy and impact of CVD risk assessment. To assess impact, they considered randomised controlled trials (RCTs) of healthcare professionals using a CVD risk score to aid in primary prevention, relative to usual care, in populations predominantly free from symptomatic CVD (table 1). Although the authors identified 31 primary studies, the majority of the studies assessed the accuracy of CVD risk assessment and therefore were beyond the scope of our review. The authors concluded that there was little evidence to support the use of risk scores for primary prevention.

Sheridan and Crespo ${ }^{32}$ (AMSTAR 4/11) conducted a much more focused review, specifically aimed to assess the benefits and harms of physician knowledge of a global CVD risk score, relative to no formal risk assessment, in adults with no history of CVD. Although the authors only searched MEDLINE, they identified 11 primary studies, most of which were relevant to our review (table 1), and reached similar conclusions as Brindle 2006: 'surprisingly little evidence that physician knowledge of global CHD risk translates into improved clinical outcomes'. ${ }^{32}$

Sheridan et $a l^{33}$ (AMSTAR 7/11) was distinct from Sheridan 2008 in that eligible interventions were targeted at patients rather than physicians. To be eligible, studies (of any design) had to be interventions of global CVD risk information, solely or as part of a complex intervention, directed at adults with no history of CVD to determine the impact of patient-targeted risk information on patient outcomes (table 1). In this review, Sheridan et al searched multiple databases and identified 18 primary studies; most were relevant to our review. They concluded that the effect of risk information on patients may improve proximal outcomes, such as accuracy or risk perception, in those who are high risk but the effect on distal outcomes was not clear.

Waldron $e t a l^{34}$ (AMSTAR 5/11) reviewed studies of any quantitative design that used communication interventions for individualised cardiovascular risk and compared them to a control or usual care and assessed their impact on patient-related outcomes (table 1). Although the authors performed a comprehensive search, only three of the 15 primary studies identified were in actual patients-the rest were of analogue patients and therefore were not relevant to our review. The authors were unable to draw strong conclusions citing the need for better quality trials.

Van Dieren et $a l^{5}$ (AMSTAR 0/11) conducted a two-part review; the first part sought to identify risk scores that had been developed or validated for people with type two diabetes, and the second part sought to find studies aimed at assessing the impact on patient outcomes when these scores were implemented in practice (table 1). The authors therefore only searched for impact studies on the risk scores that had been identified in the former half of their review. Although the authors identified 45 primary studies, only three studies were identified from the latter half of the review and were relevant to our review. They concluded that 'the impact of applying these risk scores in clinical practice is almost completely unknown'. ${ }^{35}$

Usher-Smith $e t a l^{36}$ (AMSTAR 5/11) conducted the most recent and most comprehensive review, although the searches were conducted in 2013. The authors considered randomised or non-randomised studies of interventions consisting of the provision of a CVD risk estimate to patients, or their providers, in patients with no history of CVD (table 1). Searching MEDLINE and PubMED, they identified 17 primary studies, the vast majority of which had previously been reported by one of the aforementioned systematic reviews. However, this review was the first and only review to conduct meta-analyses, which helped draw stronger conclusions about impact. The authors concluded that global risk assessment could improve prescribing and perceived risk, but not smoking, and their meta-analyses showed no significant effect on SBP or pooled total cholesterol and low-density lipoprotein (LDL) cholesterol.

\section{Effects of interventions}

As the included reviews were of variable, but generally low quality and only one attempted meta-analysis, we conducted a post hoc analysis of the primary studies reported by included systematic reviews that met our inclusion criteria to gain further insight from the reported data. Furthermore, some of the reviews insufficiently described included primary studies. Therefore, in addition to meta-analysis, we tabulated the characteristics of included primary studies, including quality ratings for each study as reported by review authors, which are included in online S4 supplementary appendix 4. The median follow-up of all included primary studies reported by reviews was 12 months, but ranged from 2 to 36 months (see online supplementary S4 appendix 4). Most interventions used Framingham or a Framingham-derived risk score; these interventions and their controls are summarised in detail in online supplementary S4 appendix 4. None of the systematic reviews used GRADE to evaluate the quality of studies, and we therefore included GRADE tables for each outcome and subgroup in online supplementary S5 appendix 5 . 
Table 1 Characteristics of included systematic reviews

\begin{tabular}{|c|c|c|c|c|c|c|}
\hline & \multicolumn{6}{|l|}{ Systematic review ID } \\
\hline & Brindle 2006 ${ }^{31}$ & Sheridan $2008^{32}$ & Sheridan $2010^{33}$ & Waldron $2011^{34}$ & van Dieren $2012^{35}$ & Usher-Smith $2015^{36}$ \\
\hline $\begin{array}{l}\text { Review } \\
\text { objective(s) }\end{array}$ & $\begin{array}{l}\text { 'To determine the } \\
\text { accuracy of assessing } \\
\text { CVD risk in the primary } \\
\text { prevention of CVD and } \\
\text { its impact on clinical } \\
\text { outcomes' }\end{array}$ & $\begin{array}{l}\text { 'To assess whether } \\
\text { global CHD risk } \\
\text { scores result in } \\
\text { clinical benefits or } \\
\text { harms' }\end{array}$ & $\begin{array}{l}\text { 'To assess the effect of } \\
\text { providing global CHD } \\
\text { risk information to } \\
\text { adults' }\end{array}$ & $\begin{array}{l}\text { 'To compare different } \\
\text { interventions used to } \\
\text { communicate } \\
\text { cardiovascular risk and } \\
\text { assess their impact on } \\
\text { patient related } \\
\text { outcomes' }\end{array}$ & $\begin{array}{l}\text { 'To review the primary } \\
\text { prevention studies that } \\
\text { focused on the } \\
\text { development, } \\
\text { validation and impact } \\
\text { assessment of a } \\
\text { cardiovascular risk } \\
\text { model, scores or rules' }\end{array}$ & $\begin{array}{l}\text { 'To systematically review } \\
\text { whether the provision of } \\
\text { information on } \\
\text { cardiovascular disease } \\
\text { (CVD) risk to healthcare } \\
\text { professionals and patients } \\
\text { impacts their } \\
\text { decision-making, } \\
\text { behaviour and ultimately } \\
\text { patient health.' }\end{array}$ \\
\hline Population & $\begin{array}{l}\text { People 'predominantly } \\
\text { free from symptomatic } \\
\text { CVD' }\end{array}$ & $\begin{array}{l}\text { 'Adults (>18) with } \\
\text { no prior history of } \\
\text { CVD' }\end{array}$ & $\begin{array}{l}\text { 'Adults with no history } \\
\text { of CVD' }\end{array}$ & Adults $(>18)$ & $\begin{array}{l}\text { 'People with type } 2 \\
\text { diabetes' }\end{array}$ & $\begin{array}{l}\text { People 'with no history of } \\
\text { CVD' }\end{array}$ \\
\hline Intervention(s) & $\begin{array}{l}\text { 'Healthcare professional } \\
\text { using a CVD risk score } \\
\text { to aid primary } \\
\text { prevention' }\end{array}$ & $\begin{array}{l}\text { 'Physician } \\
\text { knowledge of a } \\
\text { global CHD risk } \\
\text { score' }\end{array}$ & $\begin{array}{l}\text { 'Global CHD risk } \\
\text { presentation as the } \\
\text { primary intervention or } \\
\text { part of a multipart } \\
\text { intervention' }\end{array}$ & $\begin{array}{l}\text { 'Communication } \\
\text { interventions (of any } \\
\text { format) for } \\
\text { individualised CVD } \\
\text { assessment' }\end{array}$ & $\begin{array}{l}\text { 'CVD predictions } \\
\text { models that have been } \\
\text { developed... or } \\
\text { validated in a diabetes } \\
\text { population' }\end{array}$ & $\begin{array}{l}\text { 'Intervention strategy } \\
\text { consisted of provision of a } \\
\text { CVD risk model estimate } \\
\text { to either physicians or } \\
\text { patients' }\end{array}$ \\
\hline Comparison(s) & Usual care & $\begin{array}{l}\text { 'Either simple risk } \\
\text { factor counting or } \\
\text { no formal } \\
\text { assessment of risk' }\end{array}$ & Not prespecified & $\begin{array}{l}\text { Control or usual care } \\
\text { arm }\end{array}$ & Not prespecified & $\begin{array}{l}\text { No 'provision of a CVD } \\
\text { risk model estimate' }\end{array}$ \\
\hline $\begin{array}{l}\text { Country of } \\
\text { primary } \\
\text { review author }\end{array}$ & UK & $\begin{array}{l}\text { United States of } \\
\text { America }\end{array}$ & $\begin{array}{l}\text { United States of } \\
\text { America }\end{array}$ & UK & The Netherlands & UK \\
\hline AMSTAR & $4 / 11$ & $4 / 11$ & $7 / 11$ & $5 / 11$ & $0 / 11$ & $5 / 11$ \\
\hline $\begin{array}{l}\text { Eligible study } \\
\text { designs }\end{array}$ & RCTs & Any design & Any design & $\begin{array}{l}\text { 'Any quantitative } \\
\text { design' }\end{array}$ & Not specified & $\begin{array}{l}\text { Randomised and } \\
\text { non-randomised primary } \\
\text { studies }\end{array}$ \\
\hline $\begin{array}{l}\text { Databases } \\
\text { searched }\end{array}$ & $\begin{array}{l}\text { CENTRAL, MEDLINE, } \\
\text { EMBASE, CINAHL, } \\
\text { PsycINFO, ZETOC, } \\
\text { ISI Proceedings }\end{array}$ & MEDLINE & $\begin{array}{l}\text { MEDLINE, PsycINFO, } \\
\text { CINAHL, Cochrane } \\
\text { Database }\end{array}$ & $\begin{array}{l}\text { ASSIA, CINAHL, } \\
\text { EMBASE, MEDLINE, } \\
\text { PsycINFO, Science } \\
\text { Citation Index } \\
\text { expanded }\end{array}$ & MEDLINE & MEDLINE, PubMed \\
\hline $\begin{array}{l}\text { Date of } \\
\text { database } \\
\text { search }\end{array}$ & 2004 & 2007 & 2008 & 2008 & 2011 & 2013 \\
\hline Meta-analysis? & No & No & No & No & No & Yes \\
\hline $\begin{array}{l}\text { Review method } \\
\text { of quality } \\
\text { assessment }\end{array}$ & $\begin{array}{l}\text { No formal assessment. } \\
\text { 'Information on the } \\
\text { methodological quality }\end{array}$ & $\begin{array}{l}\text { Criteria adapted } \\
\text { from the US } \\
\text { Preventive }\end{array}$ & $\begin{array}{l}\text { Criteria adapted from } \\
\text { the US Preventive } \\
\text { Services Task Force }\end{array}$ & $\begin{array}{l}\text { Downs and Black } \\
\text { checklist }\end{array}$ & Quality not assessed & $\begin{array}{l}\text { Followed critical appraisal } \\
\text { skills programme } \\
\text { guidelines }\end{array}$ \\
\hline
\end{tabular}




\begin{tabular}{|c|c|c|c|c|c|c|}
\hline & \multicolumn{6}{|l|}{ Systematic review ID } \\
\hline & Brindle $2006^{31}$ & Sheridan $2008^{32}$ & Sheridan $2010^{33}$ & Waldron $2011^{34}$ & van Dieren $2012^{35}$ & Usher-Smith $2015^{36}$ \\
\hline $\begin{array}{l}\text { Review authors' } \\
\text { conclusions }\end{array}$ & $\begin{array}{l}\text { of the trials including the } \\
\text { method of } \\
\text { randomisation, } \\
\text { concealment of } \\
\text { allocation, baseline } \\
\text { group comparisons and } \\
\text { blind outcome } \\
\text { assessment was } \\
\text { collected' } \\
\text { 'Evidence supporting } \\
\text { the use of } \\
\text { cardiovascular risk } \\
\text { scores for primary } \\
\text { prevention is scarce' }\end{array}$ & $\begin{array}{l}\text { We found } \\
\text { surprisingly little } \\
\text { evidence that } \\
\text { physician } \\
\text { knowledge of } \\
\text { global CHD risk } \\
\text { currently translates } \\
\text { into improved } \\
\text { clinical outcomes' }\end{array}$ & $\begin{array}{l}\text { 'Global CHD risk } \\
\text { information seems to } \\
\text { improve the accuracy of } \\
\text { risk perception and may } \\
\text { increase intent to } \\
\text { initiate CHD prevention } \\
\text { among individuals at } \\
\text { moderate to high risk. } \\
\text { The effect of global risk } \\
\text { presentation on more } \\
\text { distal outcomes is less } \\
\text { clear and seems to be } \\
\text { related to the intensity } \\
\text { of accompanying } \\
\text { interventions.' }\end{array}$ & $\begin{array}{l}\text { 'Better quality trials are } \\
\text { needed that compare } \\
\text { different risk } \\
\text { presentation formats } \\
\text { before conclusions can } \\
\text { be drawn' }\end{array}$ & $\begin{array}{l}\text { 'The impact of } \\
\text { applying these risk } \\
\text { scores in clinical } \\
\text { practice is almost } \\
\text { completely unknown, } \\
\text { but their use is } \\
\text { recommended in } \\
\text { various national } \\
\text { guidelines.' }\end{array}$ & $\begin{array}{l}\text { 'There seems evidence } \\
\text { that providing CVD risk } \\
\text { model estimates to } \\
\text { professionals and patients } \\
\text { improves perceived CVD } \\
\text { risk and medical } \\
\text { prescribing, with little } \\
\text { evidence of harm on } \\
\text { psychological well- being.' }\end{array}$ \\
\hline
\end{tabular}


Primary outcomes

\section{Mortality}

No reviews included studies reporting CVD-related or all-cause mortality (table 2 ).

\section{CVD morbidity}

No reviews included studies reporting CVD-morbidity (table 2).

\section{Secondary outcomes}

Systolic blood pressure

Five reviews reported a total of 12 unique primary studies $(n=23346) \quad$ (see online supplementary S4 appendix 4). Of the 12 primary studies, 3 were cluster RCTs, 8 were RCTs and 1 was an observational follow-up of an RCT. Nine of the controlled trials $(n=7537)$ were reported with sufficient data to meta-analyse, resulting in a mean difference of mean change of SBP of $-2.22 \mathrm{~mm} \mathrm{Hg}(95 \%$ CI -3.49 to -0.95 ; $\mathrm{I}^{2}=66 \%$; GRADE: very low) (figure 2; table 2). Subgroup analyses by studies of interventions targeting the patient $(n=3)$, provider $(n=3)$ or both $(n=3)$, resulted in mean differences of $-4.88 \mathrm{~mm} \mathrm{Hg}(95 \% \mathrm{CI}$ -8.57 to $-1.19 ; \quad \mathrm{I}^{2}=0 \%$; GRADE: very low), $-1.14 \mathrm{~mm} \mathrm{Hg} \quad\left(95 \%\right.$ CI -2.09 to $-0.19 ; \quad \mathrm{I}^{2}=46 \%$; GRADE: low) and $-2.77 \mathrm{~mm} \mathrm{Hg}(95 \%$ CI -5.91 to $0.37 ; \mathrm{I}^{2}=76 \%$; GRADE: very low), respectively, in the intervention group relative to control (figure 2; table 2). We imputed the SE of Lovibond (1986); excluding this study from the meta-analysis did not significantly change the results of the subgroup analysis or overall estimate: $-4.82 \mathrm{~mm} \mathrm{Hg} \quad(95 \%$ CI -9.36 to -0.27 ; $\left.\mathrm{I}^{2}=0 \%\right)$ and $-2.12 \mathrm{~mm} \mathrm{Hg}(95 \%$ CI -3.41 to -0.83 ; $\mathrm{I}^{2}=68 \%$ ), respectively.

Two additional patient-directed studies were identified. The first, an RCT, $^{37}$ evaluated the impact of health checks which comprised a Framingham-derived risk score and counselling about risk, relative to usual care, in middle-aged adults. The study found a difference in SBP of $-2.5 \mathrm{~mm} \mathrm{Hg}(95 \%$ CI -3.7 to -1.3$)$ between the intervention and control group after 3 years; however, this was not adjusted to baseline values. $^{33}$ The second, an observational follow-up of an $\mathrm{RCT}^{38}$ found no significant difference between patients who received their risk score along with a decision analysis tool, relative to usual care, after 3 years: adjusted difference of SBP between intervention and control at follow-up was $0.94 \mathrm{~mm} \mathrm{Hg}(95 \%$ CI -3.2 to 5.1 , p value $0.65)$.

Finally, one RCT, targeting patients and providers, trained nurses on risk factor measurement and counselling, and provided patients with a CVD risk score and two to six sessions of counselling. ${ }^{39}$ Compared with usual care after 1 year, unadjusted differences in SBP between intervention and control were $-7.3 \mathrm{~mm} \mathrm{Hg}$ ( $\mathrm{p}$ value not reported) and $-6.2 \mathrm{~mm} \mathrm{Hg}$ ( $\mathrm{p}$ value not reported), in men and women, respectively. $^{33}$

\section{Cholesterol}

Six reviews reported a total of nine RCTs and one cluster RCT (see online supplementary S4 appendix 4). We considered total cholesterol and LDL cholesterol, and analysed them separately.

\section{Total cholesterol}

Of the seven trials $(n=23406)$ reporting total cholesterol, five $(n=7813)$ were reported with sufficient data to meta-analyse, resulting in a mean difference of $-0.11 \mathrm{mmol} / \mathrm{L}\left(95 \%\right.$ CI $-0.20,-0.02 ; \mathrm{I}^{2}=72 \%$; GRADE: very low) (figure 3; table 2). Subgroup analyses by studies of interventions targeting the patient $(n=2)$, provider $(n=1)$ or both $(n=2)$, resulted in mean differences of $-0.07 \mathrm{mmol} / \mathrm{L}\left(95 \% \mathrm{CI}-0.13,-0.02 ; \mathrm{I}^{2}=0 \%\right.$; GRADE: very low $), \quad-0.01 \mathrm{mmol} / \mathrm{L} \quad(95 \%$ CI -0.08 to 0.06 ; GRADE: very low) and $-0.26 \mathrm{mmol} / \mathrm{L}(95 \% \mathrm{CI}-0.38$ to -0.15 ; $\mathrm{I}^{2}=0 \%$; GRADE: very low) (figure 3; table 2).

Two additional RCTs were reported, one targeting patients and one targeting patients and providers. The former, ${ }^{37}$ evaluated the impact of health checks which comprised a Framingham-derived risk score and counselling about risk, relative to usual care, in middle-aged adults. The study found a difference in total cholesterol of $-0.18 \mathrm{mmol} / \mathrm{L}(95 \% \mathrm{CI}-0.26$ to -0.12$)$ between the intervention and control group after 3 years; however this was not adjusted to baseline values. ${ }^{33}$

The latter, ${ }^{39}$ targeting patients and providers, trained nurses on risk factor measurement and counselling, and provided patients with a CVD risk score and two to six sessions of counselling. ${ }^{39}$ Compared with usual care after 1 year, unadjusted differences in total cholesterol between intervention and control were $-0.13 \mathrm{mmol} / \mathrm{L}$ ( $\mathrm{p}$ value not reported) and $-0.09 \mathrm{mmol} / \mathrm{L}$ ( $\mathrm{p}$ value not reported), in men and women, respectively. ${ }^{33}$

\section{LDL cholesterol}

Five trials $(n=4940)$ reported data on LDL cholesterol, four of which $(n=4505)$ when meta-analysed yielded a greater reduction in LDL cholesterol in the intervention group compared with the control group: mean difference of $-0.15 \mathrm{mmol} / \mathrm{L} \quad\left(95 \%\right.$ CI -0.26 to $-0.05, \mathrm{I}^{2}=47 \%$; GRADE: very low) (figure 4; table 2). Subgroup analyses by studies of interventions targeting the patient $(n=3)$ and the patient and provider $(n=1)$, resulted in mean differences of $-0.15 \mathrm{mmol} / \mathrm{L}\left(95 \%\right.$ CI -0.27 to -0.03 ; $\mathrm{I}^{2}=58 \%$; GRADE: very low) and $-0.23 \mathrm{mmol} / \mathrm{L}(95 \%$ CI -0.47 to 0.01; GRADE: very low), respectively (figure 4; table 2 ).

One additional RCT targeting patients assessed the impact of mailing personalised CVD risk assessment and encouraging discussion with their primary care physician to usual care. ${ }^{40}$ The primary outcome was the occurrence of an LDL cholesterol measurement of at least $0.78 \mathrm{mmol} / \mathrm{L}(30 \mathrm{mg} / \mathrm{dL})$ lower than the baseline measurement during a 9-month follow-up. The trial showed no significant difference between intervention and control, intention-to-treat analysis resulted in an OR of $0.99(95 \%$ CI 0.56 to $1.74, \mathrm{p}=0.96) .^{40}$ 
Table 2 Meta-analysis of the impact of global cardiovascular risk assessment on cardiovascular disease morbidity, mortality, systolic blood pressure, total cholesterol, low-density lipoprotein cholesterol and smoking cessation

\begin{tabular}{|c|c|c|c|c|c|}
\hline Outcome & & Patient directed & Provider directed & $\begin{array}{l}\text { Patient and provider } \\
\text { directed }\end{array}$ & $\begin{array}{l}\text { Overall effect } \\
\text { estimate }\end{array}$ \\
\hline \multirow[t]{3}{*}{ CVD morbidity } & Effect estimate & - & - & - & - \\
\hline & $\mathrm{I}^{2}(\%)$ & - & - & - & - \\
\hline & Quality (GRADE) & - & - & - & - \\
\hline \multirow{3}{*}{$\begin{array}{l}\text { Mortality (CVD-related or } \\
\text { all-cause) }\end{array}$} & Effect estimate & - & - & - & - \\
\hline & $\mathrm{I}^{2}(\%)$ & - & - & - & - \\
\hline & Quality (GRADE) & - & - & - & - \\
\hline \multirow[t]{3}{*}{ Systolic blood pressure (mm Hg) } & Effect estimate (MD) $(95 \% \mathrm{Cl})$ & $-4.88(-8.57$ to -1.19$)$ & $-1.14(-2.09$ to -0.19$)$ & $-2.77(-5.91$ to 0.37$)$ & $-2.22(-3.49$ to -0.95$)$ \\
\hline & $\mathrm{I}^{2}(\%)$ & 0 & 46 & 76 & 66 \\
\hline & Quality (GRADE) & very low $(\bullet \circ \circ))$ & low (๑०০০) & very low (๑०০০) & very low (๑०০) \\
\hline \multirow[t]{3}{*}{ Total cholesterol (mmol/L) } & Effect estimate (MD) $(95 \% \mathrm{Cl})$ & $-0.07(-0.13$ to -0.02$)$ & $-0.01(-0.08$ to 0.06$)$ & $-0.26(-0.38$ to -0.15$)$ & $-0.11(-0.20$ to -0.02$)$ \\
\hline & $1^{2}(\%)$ & 0 & single study & 0 & 72 \\
\hline & Quality (GRADE) & very low $(\bullet \circ \circ))$ & very low (००૦०) & very low (๑०০০) & very low (๑०০০) \\
\hline \multirow[t]{3}{*}{ LDL cholesterol (mmol/L) } & Effect estimate (MD) $(95 \% \mathrm{Cl})$ & $-0.15(-0.27$ to -0.03$)$ & - & $-0.23(-0.47$ to 0.01$)$ & $-0.15(-0.26$ to -0.05$)$ \\
\hline & $\mathrm{I}^{2}(\%)$ & 58 & - & single study & 47 \\
\hline & Quality (GRADE) & very low (००००) & - & very low (००००) & very low (๑०০০) \\
\hline \multirow{3}{*}{$\begin{array}{l}\text { Smoking cessation (risk of } \\
\text { quitting) }\end{array}$} & Effect estimate (RR) $(95 \% \mathrm{Cl})$ & 1.53 (1.07 to 2.19$)$ & $1.90(0.43$ to 8.29$)$ & $0.30(0.01$ to 7.07$)$ & 1.62 (1.08 to 2.43$)$ \\
\hline & $\mathrm{I}^{2}(\%)$ & 0 & 57 & single study & 17 \\
\hline & Quality (GRADE) & low (○०००) & very low (๑०০০) & moderate $(\bullet \circ \bullet)$ & low (○०००) \\
\hline
\end{tabular}

Subgroup analyses were performed by interventions targeting the patient, the provider or both.

LDL, low-density lipoprotein; MD, mean difference, the difference of the mean differences from baseline to follow-up of the intervention arm compared with the control arm; RR, risk ratio. 


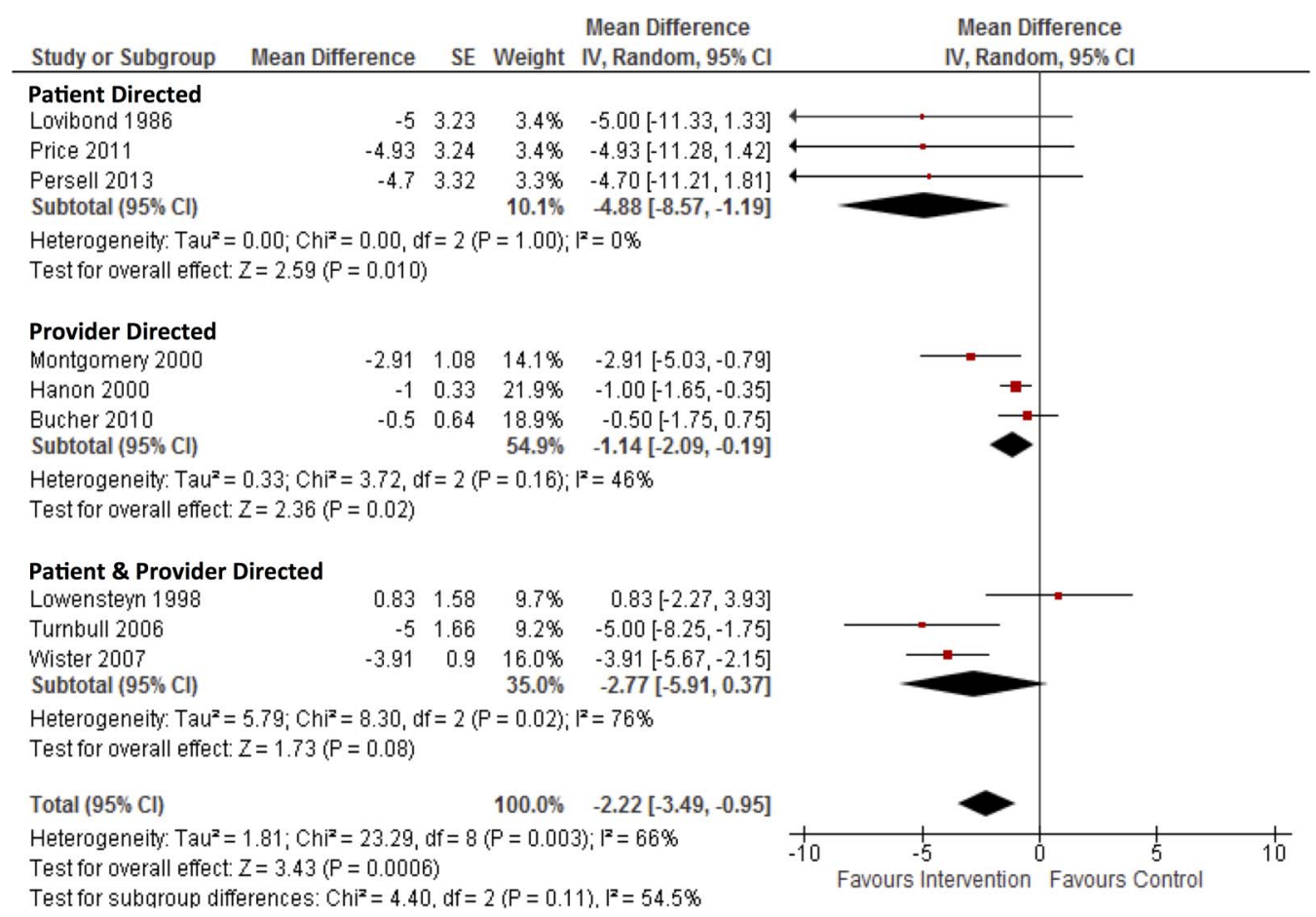

Figure 2 Forest plot and meta-analysis of the mean difference of mean change in systolic blood pressure $(\mathrm{mm} \mathrm{Hg})$ from baseline to follow-up between intervention and control groups.

\section{Smoking}

Three reviews reported a total of eight RCTs and one cluster RCT and ( $\mathrm{n}=19$ 873) (see online supplementary S4 appendix 4). Seven of these trials $(n=4131)$ were reported with sufficient data to meta-analyse, resulting in a risk ratio for quitting smoking of 1.62 (95\% CI 1.08 to 2.43 ; $\mathrm{I}^{2}=17 \%$; GRADE: low) (figure 5 ; table 2). Subgroup analyses by studies of interventions targeting the patient $(n=4)$, provider $(n=2)$ or patient and provider $(\mathrm{n}=1)$ resulted in risk ratios of $1.53(95 \% \mathrm{CI}$ 1.07 to 2.19 ; $\mathrm{I}^{2}=0 \%$; GRADE: low), 1.90 (95\% CI 0.43 to 8.29; $\mathrm{I}^{2}=57 \%$; GRADE: very low) and 0.30 (95\% CI 0.01 to 7.07; GRADE: moderate), respectively (figure 5; table 2).

Two additional RCTs were reported by included reviews, one targeted patients and one targeted patients and providers. Of the former, one RCT targeting patients assessed the impact of mailing personalised

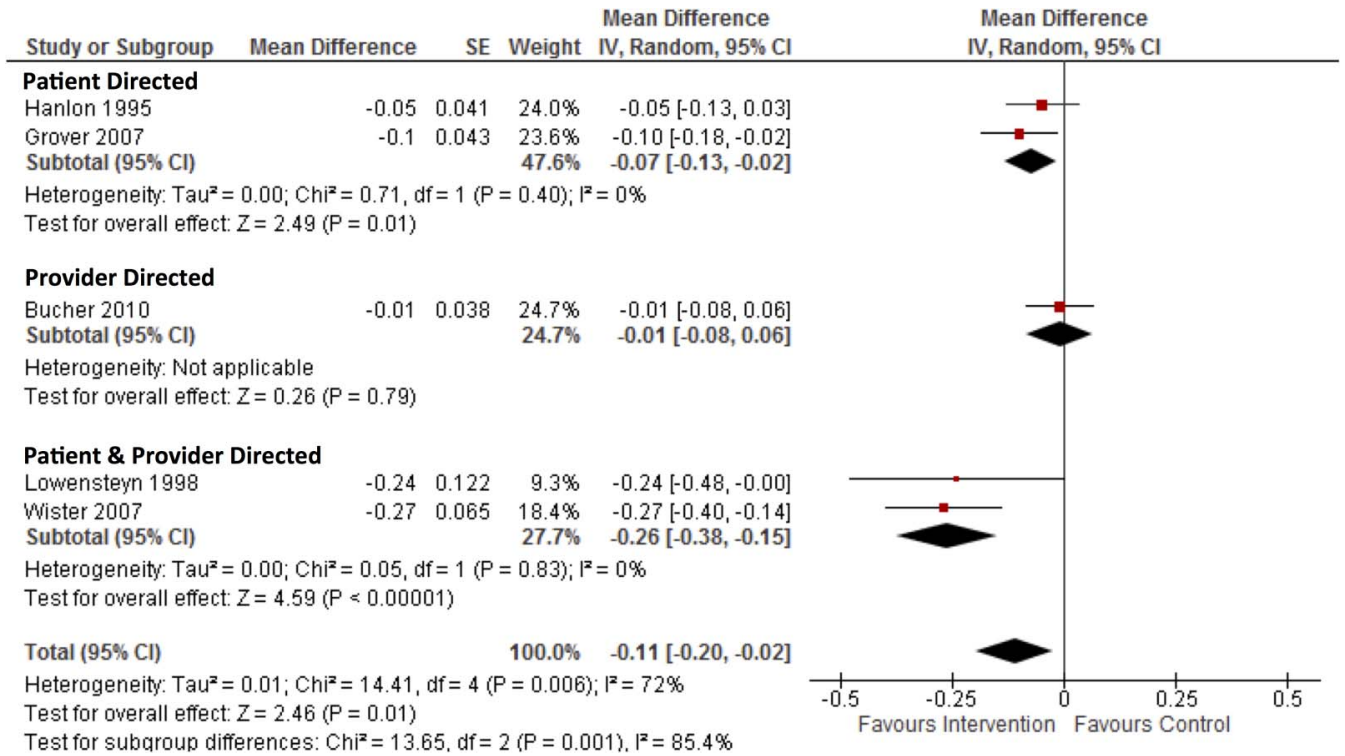

Figure 3 Forest plot and meta-analysis of the mean difference of mean change in total cholesterol $(\mathrm{mmol} / \mathrm{L})$ from baseline to follow-up between intervention and control group. 


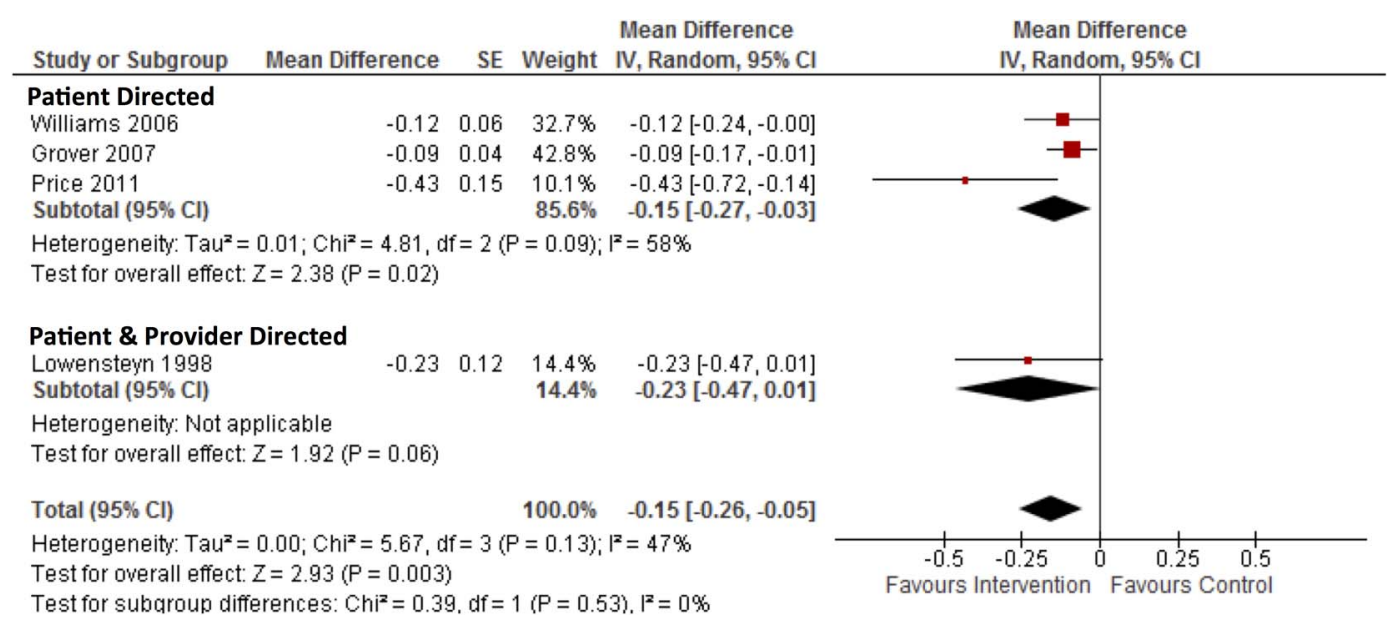

Figure 4 Forest plot and meta-analysis of the mean difference of mean change in LDL cholesterol ( $\mathrm{mmol} / \mathrm{L}$ ) from baseline to follow-up between intervention and control group. LDL, low-density lipoprotein.

CVD risk assessment and encouraging discussion with their primary care physician to usual care. ${ }^{40}$ As a secondary outcome, the trial sought to record the number of smokers who quit after nine months, but failed to provide the actual data stating, 'non-smoking (among smokers) was rare and did not vary by group'. 40

The other, an RCT targeting patients and providers, trained nurses on risk factor measurement and counselling, and provided patients with a CVD risk score and two to six sessions of counselling. ${ }^{39}$ Compared with usual care after one year, unadjusted differences in smoking prevalence between intervention and control were $-4.1 \%$ ( $p$ value not reported) and $-2.9 \%$ ( $p$ value not reported), in men and women, respectively. ${ }^{33}$

\section{DISCUSSION}

To the best of our knowledge, this is the first systematic review of systematic reviews on the impact of global cardiovascular risk assessment in the primary prevention of CVD. Reviews on this topic vary in the databases searched, search strategies used and the specific populations and interventions of interest, and their quality was generally poor (mean AMSTAR 4.2/11, range 0/11 to $7 / 11$ ). However, they have consistently reported uncertainty about the effectiveness of global CVD risk assessment. Our results show that to date, no reviews or their included primary studies have reported CVD-related morbidity or mortality or all-cause mortality. Post hoc analysis of data reported by included reviews illustrated

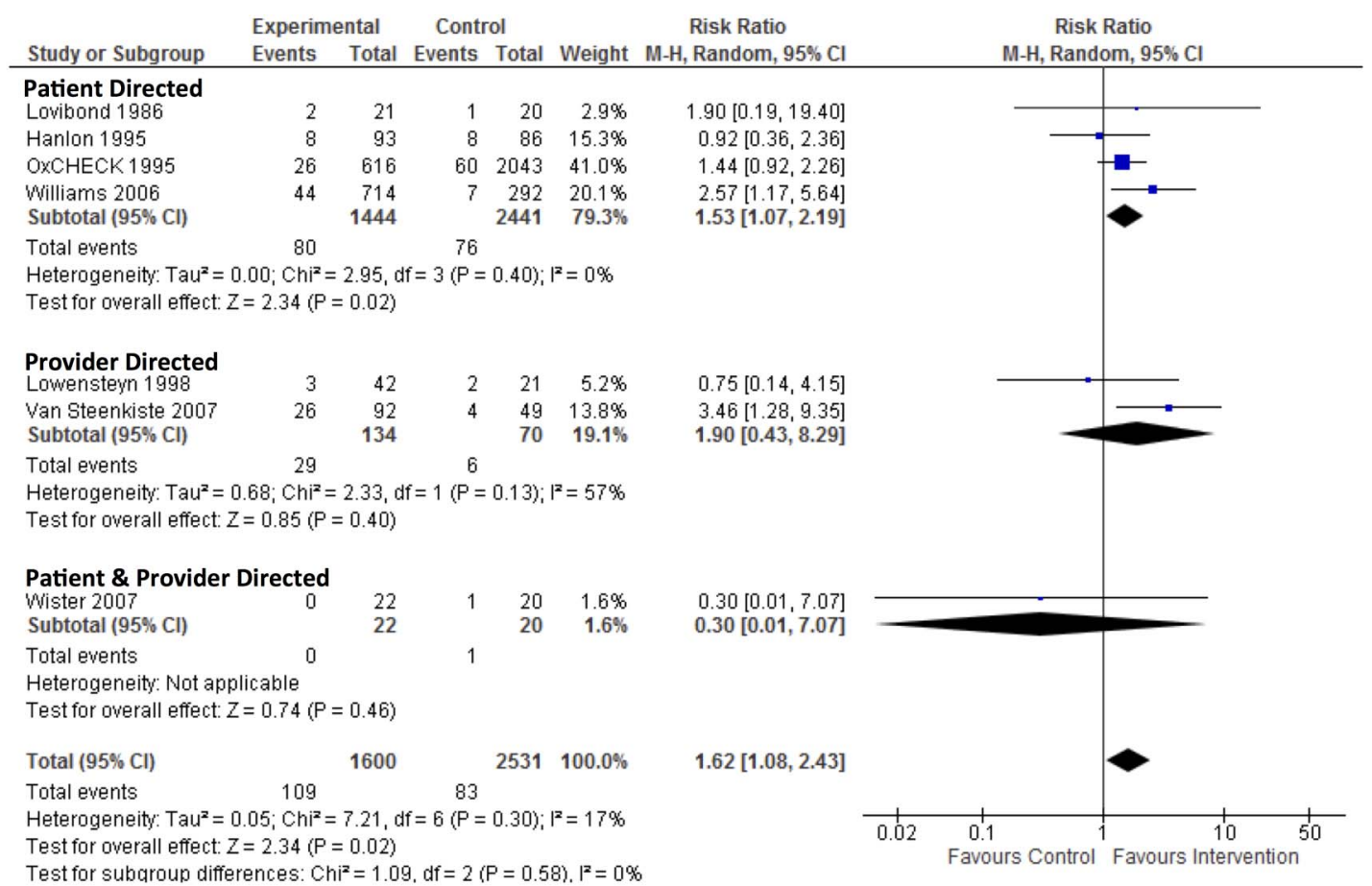

Figure 5 Forest plot and meta-analysis of the risk ratio of quitting smoking from baseline to follow-up between intervention and control group. 
very low-quality evidence for small reductions in SBP, total cholesterol, LDL cholesterol and low-quality evidence for small increases in smoking cessation.

We conducted a post hoc analysis of data reported by included systematic reviews to compensate for the poor evidence synthesis of some of the included reviews and to reduce research waste. Several of the included reviews highlighted a need for better quality trials on this topic, and our quality appraisal using GRADE corroborates these conclusions. Our post hoc analysis illustrated that all effect estimates were of low GRADE or very low GRADE quality. Our meta-analyses of data reported by systematic reviews, although not the primary aim of our systematic review, advances our knowledge on the impact of total cardiovascular risk assessment beyond what was reported by individual systematic reviews. Given the disparate and poor quality of data reporting and quality appraisal of the included systematic reviews, we felt it was responsible to perform better quality evidence synthesis and quality appraisal.

Our meta-analysis of SBP added five additional RCTs compared with the previously reported meta-analysis ${ }^{36}$ and revealed for the first time a statistically significant small reduction in SBP. We also report for the first time statistically significant, but small, reductions in total cholesterol, LDL cholesterol and smoking. These results might be explained by improvements in the prescription of cholesterol-lowering and blood pressure-lowering treatment, ${ }^{36}$ and increasing accuracy of patient risk perception. ${ }^{33} 36$

Reductions in SBP, LDL cholesterol and smoking tended to be greatest when cardiovascular risk information was directed at patients. The delineation between patient-directed and provider-directed interventions is not well resolved, since patients may discuss risk information with their provider and vice versa. This phenomenon may contaminate the subgroup analysis. A previous review ${ }^{33}$ concluded that greater effects were seen in patients with increased baseline CVD risk; adjusting for baseline CVD risk in our analyses did not explain the observed trend toward patient-directed interventions.

Observed reductions in blood pressure, cholesterol and smoking could lead to reductions in overall risk and eventual reduction in CVD events. For this to be true, such changes must be sustained long term to have a meaningful impact on event rates in individual patients. However, the median follow-up of all eligible studies reported by included systematic reviews was only 12 months. Therefore, we can have little confidence from the systematic review literature in the prospective use of CVD risk scores translating into long-term clinical benefits.

There seems to be a widespread acceptance, including among several guidelines, of total cardiovascular risk assessment despite no systematic review evidence for its effectiveness on long-term patient outcomes: neither the National Institute of Health and Care Excellence
$(\mathrm{NICE})^{8}$ or $\mathrm{WHO}^{41}$ currently acknowledge this evidence gap. However, the 2013 American College of Cardiology (ACC)/American Heart Association (AHA) Guideline on the Assessment of Cardiovascular risk acknowledges that 'none of the risk assessment tools... have been formally evaluated in randomised controlled trials... with clinical events as outcomes'. ${ }^{42}$ NICE does go so far as to make recommendations for research, but overlooks the need to evaluate the global CVD risk approach. ${ }^{43}$ Further, global cardiovascular risk assessment is included in the Quality and Outcomes Framework in the UK as an incentive for general practitioners to be compliant with guidance for primary prevention. ${ }^{44}$

There is evidence, from studies retrospectively risk scoring patients, that the absolute reduction in CVD events from cholesterol-lowering and blood pressurelowering treatment is associated with baseline CVD risk. ${ }^{45}{ }^{46}$ It is important to distinguish, however, that these data do not illustrate that the prospective use of global CVD risk assessment improves patient outcomes, but suggest that targeting high-risk patients is an efficient way to allocate resources to reduce CVD events. Nor do studies of calibration and discrimination imply effectiveness.

We speculate the paucity of data may partly be explained by the assumption that accuracy of risk scores is a proxy for effectiveness, therefore undermining rationale for further study. While mechanical prediction, such as the use of global cardiovascular risk assessment, is generally a superior method of data combination than clinical judgement; ${ }^{47}$ it is unknown whether this holds true for cardiovascular risk. Moreover, clinicians still rely on clinical judgement to integrate risk scores within the broader context of the patient-especially for risk factors that are not included in the risk assessment algorithm-therefore risk stratification is not strictly a practice that can be replaced with mechanical prediction. The uncertainty around the clinical utility of this practice has been highlighted by UK general practitioners, who expressed that broad implementation created considerable confusion, and emphasised the need for simplification and for guidance to be updated to reflect how risk scores are actually used. ${ }^{15}$

\section{Strengths and limitations}

Our systematic review of systematic reviews was strengthened by its broad inclusion criteria, which reduced the chance we missed relevant literature and allowed us to include reviews whose primary objective may not have been assessing the impact of risk assessment. This method provides quality appraised systematic reviews and their primary studies and therefore can help inform policy and practice, in addition to providing new insight from rigorous data synthesis from a breadth of sources. It also highlights trends in the systematic review literature. While there was heterogeneity in the risk scores used, the exact nature of the interventions, comparisons, follow-up time and patient demographics, we feel that 
such heterogeneity approximates the reality of clinical practice. The results therefore provide a good approximation of impact.

While we believe we have taken steps to ensure an exhaustive search, it is possible some systematic reviews were missed. Our post hoc analysis of primary studies reported by included systematic review should be interpreted with caution. Its purpose is to better appraise and synthesise the primary studies which are already available in the systematic review literature, and therefore it does not represent the conclusions from a systematic review of individual primary studies, and it is possible that further primary studies exist. Given that these data were not appraised and synthesised to a high standard in the included systematic reviews, we felt it necessary to do so. There are likely further primary studies that can add to our meta-analysis, and highquality systematic reviews should be conducted and these analyses should be updated. We were unable to perform sensitivity analyses due to a paucity of data. We did not contact authors of primary studies, which may have allowed us to adjust unadjusted study results which we were forced to report narratively. However, as these studies were reported in systematic reviews, some of which contacted study authors, we believe the likelihood of further data becoming available to be minimal, and the findings of these studies did not contradict our overall findings of the meta-analyses. In addition, we did not assess publication bias and reporting bias, not least because of the paucity of evidence, which may lead to overestimations of the effective sizes. We imputed the SE of one study, ${ }^{48}$ which may underestimate heterogeneity; however sensitivity analysis revealed only a $2 \%$ absolute increase in $\mathrm{I}^{2}$ for the overall effect estimate when this study was excluded. The current evidence base is limited in that all patients were from high-income countries, many were hypertensive and most interventions used a Framingham-derived risk score.

\section{Implications for research and practice}

The findings of our post hoc meta-analyses should be interpreted for practice with caution given the paucity of evidence and its low quality. Policymakers worldwide should take care when implementing global cardiovascular risk approaches, especially in an era where prevention efforts are expanding worldwide, as there was no systematic review evidence to suggest that the prospective use of global cardiovascular risk assessment in clinical practice reduces CVD events. Although the most recent systematic review was published in 2015, its literature search was conducted in 2013. Researchers should therefore update and improve the quality of systematic reviews and focus on CVD-related morbidity and mortality and other hard patient outcomes. In some jurisdictions, such as many low-income and middle-income countries, high-quality primary studies may be needed and these should be done before the widespread implementation of CVD risk scoring or, if not possible, in concert.

\section{CONCLUSION}

There is currently no evidence from systematic reviews that the prospective use of global cardiovascular risk assessment translates to reductions in CVD events. Systematic reviews, which were generally of poor quality, have consistently reported uncertainty about the impact of this practice on meaningful patient outcomes. These reviews found no studies reporting CVD-related morbidity or mortality, and the reductions in SBP, cholesterol and smoking may not be clinically significant given their small effect size and short duration. Despite the widespread popularity of global cardiovascular risk assessment, resources need to be directed in the first instance to conduct high-quality systematic reviews, and further RCTs powered to measure CVD-related morbidity and mortality may be needed.

Contributors DRJC conceived of the study, screened articles, extracted data, analysed the data and wrote the manuscript. ACT screened articles, extracted data, contributed to analysis and manuscript writing. IJO contributed to GRADE appraisal, analysis and manuscript writing. NR reviewed and contributed to the database search strategies. AMW contributed to the analysis and manuscript writing. CJH contributed to the methodological approach, the analysis and manuscript writing

Funding This research received no specific grant from any funding agency in the public, commercial or not-for-profit sectors.

Competing interests None declared.

Provenance and peer review Not commissioned; externally peer reviewed.

Data sharing statement No additional data are available.

Open Access This is an Open Access article distributed in accordance with the Creative Commons Attribution Non Commercial (CC BY-NC 4.0) license, which permits others to distribute, remix, adapt, build upon this work noncommercially, and license their derivative works on different terms, provided the original work is properly cited and the use is non-commercial. See: http:// creativecommons.org/licenses/by-nc/4.0/

\section{REFERENCES}

1. World Health Organization. Cardiovascular diseases (CVDs). 2015 http://www.who.int/mediacentre/factsheets/fs317/en/ (accessed 4 Aug 2015).

2. WHO. Noncommunicable diseases, fact sheet. 2015. http://www. who.int/mediacentre/factsheets/fs355/en/

3. Mathers CD, Loncar D. Projections of global mortality and burden of disease from 2002 to 2030. PLoS Med 2006;3:e442.

4. Roth GA, Huffman MD, Moran AE, et al. Global and regional patterns in cardiovascular mortality from 1990 to 2013. Circulation 2015;132:1667-78.

5. Pearson TA, Blair SN, Daniels SR, et al. AHA guidelines for primary prevention of cardiovascular disease and stroke: 2002 update: consensus panel guide to comprehensive risk reduction for adult patients without coronary or other atherosclerotic vascular diseases. American Heart Association Science Advisory and Coordinating Committee. Circulation 2002;106:388-91.

6. National Institute for Health and Care Excellence. Lipid modification: cardiovascular risk assessment and the modification of blood lipids for the primary and secondary prevention of cardiovascular disease. 2015. https://www.nice.org.uk/guidance/cg181/resources/guidancelipid-modification-cardiovascular-risk-assessment-and-themodification-of-blood-lipids-for-the-primary-and-secondaryprevention-of-cardiovascular-disease-pdf

7. WHO. Package of essential noncommunicable (PEN) disease interventions for primary health care in low-resource settings. Geneva, Switzerland. 2010. http://apps.who.int/iris/handle/10665/ 44260 (accessed 27 Oct 2014)

8. NICE. Cardiovascular risk assessment and the modification of blood lipids for the primary and secondary prevention of cardiovascular 
disease: methods, evidence, and recommendations. Published online first. 2014. http://www.nice.org.uk/guidance/cg181/evidence/ lipid-modification-update-full-guideline-243786637

9. Tang L, Patao C, Chuang J, et al. Cardiovascular risk factor control and adherence to recommended lifestyle and medical therapies in persons with coronary heart disease (from the National Health and Nutrition Examination Survey 2007-2010). Am J Cardiol 2013;112:1126-32

10. McFarlane SI, Jacober SJ, Winer N, et al. Control of cardiovascular risk factors in patients with diabetes and hypertension at urban academic medical centers. Diabetes Care 2002;25:718-23.

11. Pearson TA, Laurora I, Chu $\mathrm{H}$, et al. The lipid treatment assessment project (L-TAP): a multicenter survey to evaluate the percentages of dyslipidemic patients receiving lipid-lowering therapy and achieving low-density lipoprotein cholesterol goals. Arch Intern Med 2000;160:459-67.

12. Wolf-Maier K, Cooper RS, Kramer H, et al. Hypertension treatment and control in five European countries, Canada, and the United States. Hypertension 2004;43:10-17.

13. Hajjar I, Kotchen TA. Trends in prevalence, awareness, treatment, and control of hypertension in the United States, 1988-2000. JAMA 2003;290:199-206.

14. Camisasca $\mathrm{P}$, Avanzini F, Alli $\mathrm{C}$, et al. Overall cardiovascular risk still ignored in general practice care of hypertension. J Cardiovasc Risk 2002;9:147-52.

15. Liew SM, Blacklock C, Hislop J, et al. Cardiovascular risk scores: qualitative study of how primary care practitioners understand and use them. Br J Gen Pract 2013;63:e401-7.

16. Williams CL, Bollella M, Wynder E. Preventive cardiology in primary care. Atherosclerosis 1994;108(Suppl):S117-26.

17. Goldman RE, Parker DR, Eaton CB, et al. Patients' perceptions of cholesterol, cardiovascular disease risk, and risk communication strategies. Ann Fam Med 2006;4:205-12.

18. van Steenkiste B, van der Weijden T, Timmermans $D$, et al. Patients' ideas, fears and expectations of their coronary risk: barriers for primary prevention. Patient Educ Couns 2004;55:301-7.

19. Conroy RM, Pyörälä K, Fitzgerald AP, et al. Estimation of ten-year risk of fatal cardiovascular disease in Europe: the SCORE project. Eur Heart J 2003;24:987-1003.

20. D'Agostino RBS, Grundy S, Sullivan LM, et al. Validation of the Framingham coronary heart disease prediction scores: results of a multiple ethnic groups investigation. JAMA 2001;286:180-7.

21. Hippisley-Cox J, Coupland C, Vinogradova Y, et al. Derivation and validation of QRISK, a new cardiovascular disease risk score for the United Kingdom: prospective open cohort study. BMJ 2007;335:136

22. Thomsen TF, McGee D, Davidsen M, et al. A cross-validation of risk-scores for coronary heart disease mortality based on data from the Glostrup Population Studies and Framingham Heart Study. Int $J$ Epidemiol 2002;31:817-22.

23. Higgins JPT, Green S, eds. Cochrane Handbook for Systematic Reviews of Interventions Version 5.1.0 [updated March 2011]. The Cochrance Collaboration, 2011. www.cochrane-handbook.org

24. Collins D, Tompson A, Roberts N, et al. Global cardiovascular risk assessment in the primary prevention of cardiovascular diseases in adults: an overview of systematic reviews. PROSPERO Int. Prospect. Regist. Syst. Rev. 2015. http://www.crd.york.ac.uk/PROSPERO/ display record.asp?ID=CRD42015019821 (accessed 4 Aug 2015)

25. Emberson JR, Whincup PH, Morris RW, et al. Re-assessing the contribution of serum total cholesterol, blood pressure and cigarette smoking to the aetiology of coronary heart disease: impact of regression dilution bias. Eur Heart J 2003;24:1719-26.

26. Cooper A, Nherera L, Calvert N, et al. Clinical guidelines and evidence review for lipid modification: cardiovascular risk assessment and the primary and secondary prevention of cardiovascular disease. London: National Collaborating Centre for Primary Care and Royal College of General Practitioners 2008;1-241.

27. Shea BJ, Grimshaw JM, Wells GA, et al. Development of AMSTAR a measurement tool to assess the methodological quality of systematic reviews. BMC Med Res Methodol 2007;7:10.
28. Review Manager (RevMan) [Computer program]. Version 5.3. Copenhagen: The Nordic Cochrane Centre, The Cochrane Collaboration, 2014

29. Guyatt $\mathrm{GH}$, Oxman AD, Vist GE, et al. GRADE: an emerging consensus on rating quality of evidence and strength of recommendations. BMJ 2008;336:924-6.

30. GRADEpro GDT. GRADEpro Guideline Development Tool. 2015. http://www.gradepro.org.

31. Brindle P, Beswick A, Fahey T, et al. Accuracy and impact of risk assessment in the primary prevention of cardiovascular disease: a systematic review. Heart 2006;92:1752-9.

32. Sheridan SL, Crespo E. Does the routine use of global coronary heart disease risk scores translate into clinical benefits or harms? A systematic review of the literature. BMC Health Serv Res 2008;8:60.

33. Sheridan SL, Viera AJ, Krantz MJ, et al. The effect of giving global coronary risk information to adults. Arch Intern Med 2010;170:230-9.

34. Waldron C-A, van der Weijden T, Ludt S, et al. What are effective strategies to communicate cardiovascular risk information to patients? A systematic review. Patient Educ Couns 2011;82: 169-81.

35. van Dieren S, Beulens JWJ, Kengne AP, et al. Prediction models for the risk of cardiovascular disease in patients with type 2 diabetes: a systematic review. Heart 2012;98:360-9.

36. Usher-Smith JA, Silarova B, Schuit E, et al. Impact of provision of cardiovascular disease risk estimates to healthcare professionals and patients: a systematic review. BMJ Open 2015;5:e008717.

37. Effectiveness of health checks conducted by nurses in primary care: final results of the OXCHECK study. Imperial Cancer Research Fund OXCHECK Study Group. BMJ 1995;310:1099-104.

38. Emmett CL, Montgomery AA, Peters TJ, et al. Three-year follow-up of a factorial randomised controlled trial of two decision aids for newly diagnosed hypertensive patients. Br J Gen Pract 2005;55:551-3.

39. Randomised controlled trial evaluating cardiovascular screening and intervention in general practice: principal results of British family heart study. Family Heart Study Group. BMJ 1994;308:313-20

40. Persell SD, Lloyd-Jones DM, Friesema EM, et al. Electronic health record-based patient identification and individualized mailed outreach for primary cardiovascular disease prevention: a cluster randomized trial. J Gen Intern Med 2013;28:554-60.

41. WHO. Prevention of cardiovascular disease: guidelines for the assessment and managment of cardiovascular risk. 2007. http:// www.who.int/cardiovascular diseases/guidelines/Fulltext.pdf

42. Goff DCJ, Lloyd-Jones DM, Bennett G, et al. 2013 ACC/AHA guideline on the assessment of cardiovascular risk: a report of the American College of Cardiology/American Heart Association Task Force on Practice Guidelines. Circulation 2014;129:S49-73.

43. NICE. Cardiovascular risk assessment and the modification of blood lipids for the primary and secondary prevention of cardiovascular disease: appendices. Published online first. 2014. http://www.nice. org.uk/guidance/cg181/evidence/lipid-modification-updateappendices-243786638

44. NHS Employers. 2015/16 General Medical Services (GMS) contract Quality and Outcomes Framework (QOF). 2015. http://www. nhsemployers.org/ /media/Employers/Documents/Primary care contracts/QOF/2015—16/2015 16 QOF guidance for stakeholders. pdf

45. Sundstrom J, Arima H, Woodward M, et al. Blood pressure-lowering treatment based on cardiovascular risk: a meta-analysis of individual patient data. Lancet (London, England) 2014;384:591-8.

46. Mihaylova B, Emberson J, Blackwell L, et al. The effects of lowering LDL cholesterol with statin therapy in people at low risk of vascular disease: meta-analysis of individual data from 27 randomised trials. Lancet 2012;380:581-90.

47. Grove WM, Zald DH, Lebow BS, et al. Clinical versus mechanical prediction: a meta-analysis. Psychol Assess 2000;12:19-30.

48. Lovibond SH, Birrell PC, Langeluddecke P. Changing coronary heart disease risk-factor status: the effects of three behavioral programs. J Behav Med 1986;9:415-37. 